\title{
Evaluation of the suitability of electronic nose based on fast GC for distinguishing between the plum spirits of different geographical origins
}

\author{
Magdalena Śliwińska ${ }^{1} \cdot$ Paulina Wiśniewska $^{1} \cdot$ Tomasz Dymerski $^{1} \cdot$ \\ Waldemar Wardencki ${ }^{1} \cdot$ Jacek Namieśnik $^{1}$
}

Received: 2 September 2015 / Revised: 8 March 2016 / Accepted: 30 March 2016 / Published online: 16 April 2016

(C) The Author(s) 2016. This article is published with open access at Springerlink.com

\begin{abstract}
Plum spirits are obtained exclusively via the alcoholic fermentation and distillation of meaty plums or must composed of plums, with or without stones. The European countries such as Poland, the Slovak Republic, the Czech Republic, Bulgaria and Romania are the leading producers of this alcoholic beverage. Information about the authentication of plum spirits produced in different countries can be found in the published literature. Gas chromatography, sensory analysis and spectroscopic techniques were the most frequently used research tools in those studies. So far, there were no available published reports about the suitability of an electronic nose based on fast GC for analyzing plum spirits. The volatile fractions of six samples of four different origins (Poland, Czech Republic, the Slovakia and Romania) with $40 \%$ alcoholic content were analyzed using electronic nose based on fast GC (Heracles II). Four data analysis methods were used, namely principal component analysis, discriminant function analysis, soft independent modeling of class analogies and statistical quality control. In this work, for discrimination of results was used Euclidean distance between each sample, standard deviation and coefficient of variation. Conducted research was aimed at the evaluation of the suitability of an electronic nose based on fast GC for distinguishment between the volatile profiles of plum spirits of different geographical origins. These studies are the foundation for further work on discrimination of samples of plum spirits produced within a greater number of geographical regions.
\end{abstract}

Magdalena Śliwińska

m.e.sliwinska@gmail.com

1 Department of Analytical Chemistry, The Chemical Faculty, Gdansk University of Technology, 11/12 Narutowicza St., 80-233 Gdańsk, Poland
All the applied chemometric methods turned out to be effective.

Keywords Electronic nose - Fast GC · Plum spirits . Authenticity test $\cdot$ Geographical origin

\section{Introduction}

In Europe, 46 traditional alcoholic beverages have been classified and defined, which includes inter alia, brandy, gin, liqueurs and fruit spirits [1]. Fruits spirits have been defined in the EU regulation as spirit drinks obtained exclusively via the alcoholic fermentation and distillation of meaty fruits or must composed of fruits, berries or vegetables, with or without stones. The amount of volatile substances, which has also been defined, must not exceed $200 \mathrm{~g} / \mathrm{hl}$ of $100 \%(\mathrm{v} / \mathrm{v})$ alcohol. The content of alcohol derived from fruits must not be less than $37.5 \%$ (v/v). Fruit spirits cannot be artificially flavored [2]. The name of a given fruit spirit should contain the name of the fruit from which it has been made, e.g., cherry spirit, or "Kirsch," pear spirit, and plum spirit, or slivovitz [3].

Plum spirit is considered the most popular fruit spirit. The European countries such as Poland, the Slovak Republic, the Czech Republic, Bulgaria and Romania are the leading producers of this alcoholic beverage. Depending on the country of origin, plum spirit is known under different names, i.e., śliwowica (Poland), slivovice (the Czech Republic), tuica (Romania) and slivovica (the Slovak Republic) [3, 4]. Regardless of the country of origin of plum spirit, its production consists of the following steps: washing and pitting of plums (due to the legal regulations on the content of ethyl carbamate, a carcinogen present in the plum pits, the pits have to be removed), mashing and 
fermenting the plum pureee. The next stage is distillation which is performed in order to obtain pure spirit. The heads and tails of the distillation run are not used in the production of this alcoholic beverage. Next, the main fraction is subjected to aging. Depending on the recipe, the obtained beverage is stored in glass containers or oak barrels for a period of time ranging from 2 to 5 years [5, 6]. Additionally, in the final production stage, the plum spirit can be diluted with water to achieve the alcohol content in the range of $40-50 \%[3,4]$.

Information about the authentication of plum spirits produced in different countries can be found in the published literature. A comparative sensory evaluation and GC-MS analysis were performed on the Polish plum spirit (i.e., Śliwowica Łącka), Slovakian Pravá Bošacka Slivovica and Romanian Tzuica z Clej-Napoca [4]. Fruit spirits produced from Serbian plums were also analyzed [7-9]. The Serbian plum spirits were studied in order to, inter alia, determine the content of volatile compounds in different kinds. The composition of four plum spirits, i.e., Manastrila from Belgrade, homemade Sokolova rakija, Karanka from the Užice region and Valjevka from the Valjevko region, was analyzed and compared by means of GC-FID and sensory analysis [7]. The Serbian plum spirits were also analyzed for the presence of $\mathrm{Cu}, \mathrm{Fe}, \mathrm{Zn}, \mathrm{Mn}, \mathrm{Ca}$, Se and As using atomic absorption technique [9]. It was demonstrated that the composition of plum spirits is influenced by their geographical origin, preliminary processing, and the type and time of storage of the fruits $[3,4,7,9,10]$. Based on the cited publications, it is apparent that there are differences between the plum spirits originating from different countries in relation to the composition of volatile fraction and organoleptic properties. Gas chromatography (GC-MS [4, 11], GC-FID [7]), sensory analysis [4, 7, 11] and spectroscopic techniques were the most frequently used research tools in those studies. However, a comparison of volatile profiles of plum spirits from different countries obtained by means of an electronic nose is still lacking.

The electronic nose has been used for many years to authenticate alcoholic beverages. To this end, wines [1221], tequila, whiskey, vodkas [22, 23] and Chinese spirit [24] were analyzed. Until now, the application of electronic nose was based on sensors, e.g., conductometric, amperometric and piezoelectric sensors [25]. However, the publications dealing with the authentication of alcoholic beverages by means of electronic nose based on fast GC are becoming more frequent lately. This specific type of electronic nose generates peaks with the highest discriminatory power, which produce a characteristic volatile profile, a so-called fingerprint, when exposed to the gas mixture [25]. The electronic nose based on fast GC was used to analyze inter alia whiskey [26, 27], wines [28] and liqueurs [29, 30].
Based on a review of published literature, it was concluded that an electronic nose based on fast GC has not yet been applied to investigate the volatile profiles of fruit spirits. Thus, it is necessary to broaden the knowledge about the use of this device for determining the volatile profiles of plum spirits originating from different countries. The main research aim was to evaluate whether the aforementioned electronic nose is suitable to distinguish between the plum spirits of different geographical origins. In addition, four statistical methods, namely principal component analysis (PCA), discriminant function analysis (DFA), soft independent modeling of class analogies (SIMCA) and statistical quality control (SQC), were used to analyze the data.

\section{Materials and methods}

Six plum spirits produced in four different countries located in Central and Eastern Europe, i.e., Poland (Śliwowica Łącka), the Czech Republic (Slivovice Zlatá R. JelinekCSZ, and Slivovice R. Jelinek-CS), the Slovak Republic (Zariecka Borovicka-SZB and Maraska Sljivovica-SM) and Romania (Ţuica de Maramureş), were analyzed. All sampled plum spirits were purchased in 2013 and stored in tightly closed bottles at room temperature. The alcohol content of all beverages was $40 \% \mathrm{v} / \mathrm{v}$.

Prior to analysis, samples containing $2 \mathrm{ml}$ of plum spirit and $4 \mathrm{ml}$ of deionized water were prepared in 20 $\mathrm{ml}$ vials. Next, all samples were tightly closed with caps made of $20 \mathrm{~mm}$ thick PTFE/silicone membrane. Highpurity deionized water used for diluting the plum spirits was obtained from a MilliQ A10 Gradient/Elix System (Millipore, USA).

In this study, the electronic nose based on fast GC (Heracles II, Alpha M.O.S., France) and equipped with two capillary columns of different polarity, i.e., nonpolar MTX-5 (5 \% diphenyl) and medium polarity MXT1701 (14\% cyanopropylphenyl) with dimensions of $10 \mathrm{~m} \times 0.18 \mathrm{~mm} \times 0.4 \mu \mathrm{m}$, and two ultrasensitive flame ionization detectors ( $\mu$-FIDs), was used. The electronic nose was also equipped with an autosampler (Odour Scanner HS 100; Gerstel, Germany). Each sample was incubated for $20 \mathrm{~min}$ at $40{ }^{\circ} \mathrm{C}$, while the agitation speed was maintained at the level of $500 \mathrm{rpm}$. After incubation, only the headspace phase $(2500 \mu \mathrm{l})$ was transferred into the injector heated to $200{ }^{\circ} \mathrm{C}$. The chromatographic program consisted of the following parameters: initial temperature of $70{ }^{\circ} \mathrm{C}$ (kept for $18 \mathrm{~s}$ ), then ramped at $2{ }^{\circ} \mathrm{C} / \mathrm{s}$ to $270{ }^{\circ} \mathrm{C}$ (kept for $30 \mathrm{~s}$ ) and the detector temperature of $270{ }^{\circ} \mathrm{C}$. Hydrogen N5.0 was used as a carrier gas (Linde Gaz, Poland). Each sample was analyzed six times. 


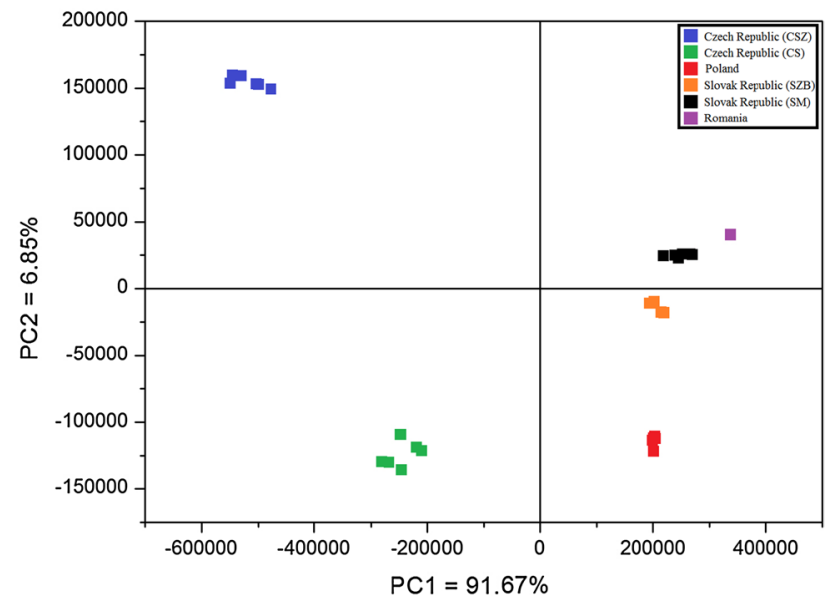

Fig. 1 The results of PCA 2D applied to plum spirits originating from different geographical regions; origin of samples was highlighted in: purple color Romania, red color Poland, green color Czech Republic (CS), blue color Czech Republic (CSZ), orange color Slovak Republic (SZB), black color Slovak Republic (SM), and six repetitions of all types of samples were done

Four statistical methods were used to analyze the data, i.e., principal component analysis (PCA), discriminant function analysis (DFA), soft independent modeling of class analogies (SIMCA) and statistical quality control (SQC) by employing Alpha Soft software (V12.4, Alpha M.O.S, Toulouse, France). The $p$ value was calculated by using MANOVA algorithm. Figures were performed by using OriginPro 8.0 and Alpha Soft software.

\section{Results and discussion}

As there were no available published reports about the suitability of an electronic nose based on fast GC for analyzing plum spirits, four statistical methods were used to analyze the obtained data. The group consists of six repetitions of one sample.

PCA was the first employed chemometric method, which enabled a graphical representation of multidimensional relationships and the reduction in the number of variables [29]. In Fig. 1, the results of PCA 2D performed on the data collected by means of an electronic nose are presented, and the data points correspond to specific groups of plum spirits. Discrimination index of PCA 2D equals 91. The sum of the first and second principal components accounted for $98.52 \%$ of data variance. PC1 accounted for $91.67 \%$ and PC2 accounted for $6.85 \%$. It is apparent that the plot can be divided into two parts. The points corresponding to plum spirits from Poland, Slovak and Romanian are in the first and fourth quadrant of the plot. All calculated Euclidean distances and coefficient of variation by program Microsoft Excel 2007 are presented in Table 1. The distance between Romanian and Slovak Republic groups is higher than the distance between two Slovak

Table 1 Calculated values of Euclidean distances and coefficient of variation between groups according to PCA and DFA results

\begin{tabular}{|c|c|c|c|c|c|c|c|c|c|}
\hline \multicolumn{2}{|l|}{ Relation between group } & \multicolumn{2}{|l|}{ PCA 2D } & \multicolumn{2}{|l|}{ PCA 3D } & \multicolumn{2}{|l|}{ DFA } & \multicolumn{2}{|l|}{ DFA 3D } \\
\hline & & E. distance & $\mathrm{CV}$ & E. distance & $\mathrm{CV}$ & E. distance & $\mathrm{CV}$ & E. distance & $\mathrm{CV}$ \\
\hline Czech Republic (CSZ) & Czech Republic (CS) & $389,901.67$ & 0.05 & $389,908.92$ & 0.05 & 854.03 & $>0.01$ & 934.59 & $>0.01$ \\
\hline Czech Republic (CSZ) & Romania & $881,791.58$ & 0.01 & $882,665.48$ & 0.01 & 1746.49 & $>0.01$ & 1746.63 & $>0.01$ \\
\hline Czech Republic (CSZ) & Poland & $721,143.65$ & 0.02 & $774,346.13$ & 0.02 & 2320.26 & $>0.01$ & 2321.97 & $>0.01$ \\
\hline Czech Republic (CSZ) & Slovak Republic (SZB) & $742,250.85$ & 0.02 & $742,375.69$ & 0.02 & 1774.57 & $>0.01$ & 1785.04 & $>0.01$ \\
\hline Czech Republic (CSZ) & Slovak Republic (SMB) & $776,962.63$ & 0.03 & $777,471.84$ & 0.03 & 1765.50 & $>0.01$ & 1772.99 & $>0.01$ \\
\hline Czech Republic (CS) & Poland & $447,156.21$ & 0.03 & $457,448.23$ & 0.03 & 1581.30 & $>0.01$ & 1607.79 & $>0.01$ \\
\hline Czech Republic (CS) & Slovak Republic (SZB) & $463,930.05$ & 0.03 & $464,205.61$ & 0.03 & 1152.28 & $>0.01$ & 1167.29 & $>0.01$ \\
\hline Czech Republic (CS) & Slovak Republic (SMB) & $515,416.07$ & 0.04 & $516,059.16$ & 0.04 & 1168.22 & $>0.01$ & 1188.16 & $>0.01$ \\
\hline Czech Republic (CS) & Romania & $359,988.56$ & 0.01 & $395,873.92$ & 0.01 & 1183.19 & $>0.01$ & 1249.62 & $>0.01$ \\
\hline Poland & Slovak Republic (SZB) & $100,580.64$ & 0.06 & $150,892.72$ & 0.06 & 621.63 & $>0.01$ & 630.29 & $>0.01$ \\
\hline Poland & Slovak Republic (SMB) & $145,981.61$ & 0.08 & $162,215.76$ & 0.08 & 663.86 & $>0.01$ & 667.96 & $>0.01$ \\
\hline Poland & Romania & $218,332.22$ & 0.01 & $258,361.29$ & 0.01 & 728.51 & $>0.01$ & 736.98 & $>0.01$ \\
\hline Slovak Republic (SZB) & Slovak Republic (SMB) & $57,300.15$ & 0.24 & $70,895.49$ & 0.24 & 60.05 & 0.02 & 67.22 & 0.01 \\
\hline Slovak Republic (SZB) & Romania & $151,929.20$ & 0.03 & $162,535.72$ & 0.03 & 166.47 & 0.01 & 255.72 & 0.01 \\
\hline Slovak Republic (SMB) & Romania & $109,448.85$ & 0.02 & $128,538.24$ & 0.02 & 77.97 & 0.02 & 201.00 & 0.01 \\
\hline
\end{tabular}

E-distance-calculated Euclidean distance between two groups

$\mathrm{CV}$ (coefficient of variation) — sum of SD from two groups divided by Euclidean distance between them 


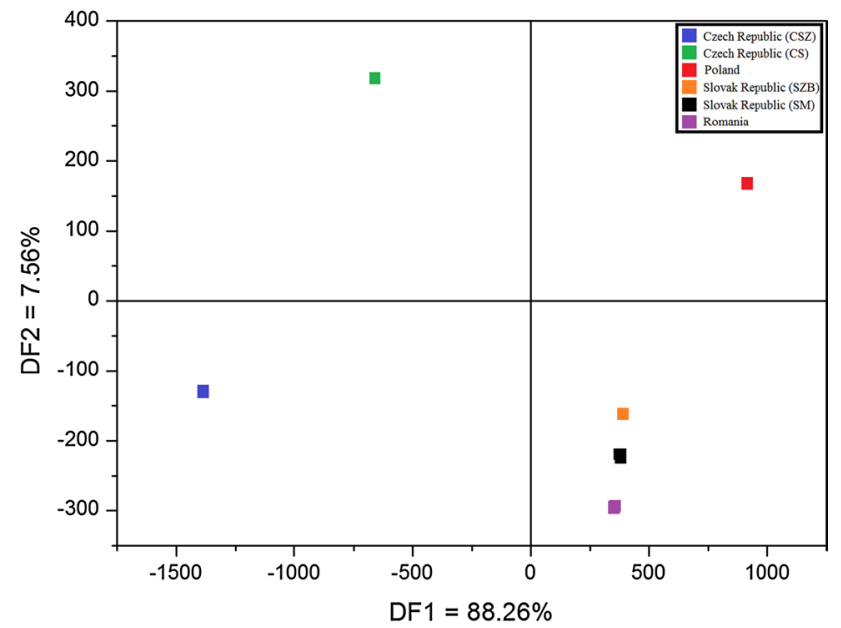

Fig. 2 The results of DFA 2D applied to plum spirits originating from different geographical regions; origin of samples was highlighted in: purple color Romania, red color Poland, green color Czech Republic (CS), blue color Czech Republic (CSZ), orange color Slovak Republic (SZB), black color Slovak Republic (SM), and six repetitions of all types of samples were done

Republic groups; additionally, the distances between Polish plum spirit group and other Slovak groups are also higher.

On the other hand, the points corresponding to two Czech Republic groups are located in second and third quadrant of the plot. These groups have largest distances between each other and other groups. It suggests that these groups differ the most from other groups, those originating from the Slovak Republic, Poland and Romania. The large distance is between points corresponding to Czech Slivovice Zlatá R. Jelinek (CSZ) and Slivovice R. Jelinek (CS), and different production process might be the reason of this observation. Czech plum spirit (CSZ) is aged in oak barrels, and it should be mentioned that the points corresponding to this group were located at the farthest distance from other spirit groups. Unfortunately, the use of PCA 2D does not allow for a clear distinction of plum spirits between their geographical origins based only on PC1 or PC2, but it allows for differentiation between groups.

DFA is a multivariate technique for describing a mathematical function, and it allows to distinguish among predefined groups of samples [25]. The DFA 2D is shown in Fig. 2. The DFA 2D method identifies DF1 and DF2 which explain $88.26 \%$ and $7.56 \%$ of the variability in the initial data set and which are represented as the axes of the DFA plot. As in the case of PCA 2D, the points corresponding to Czech plum spirits are separated by a large distance from the other samples. Moreover, the points belonging to the Czech (CSZ) group are located in the second and third quadrant of the plot and are clearly separated from the rest of the analyzed plum spirits. As with the results of the PCA, the distance between the Romanian and Slovakian

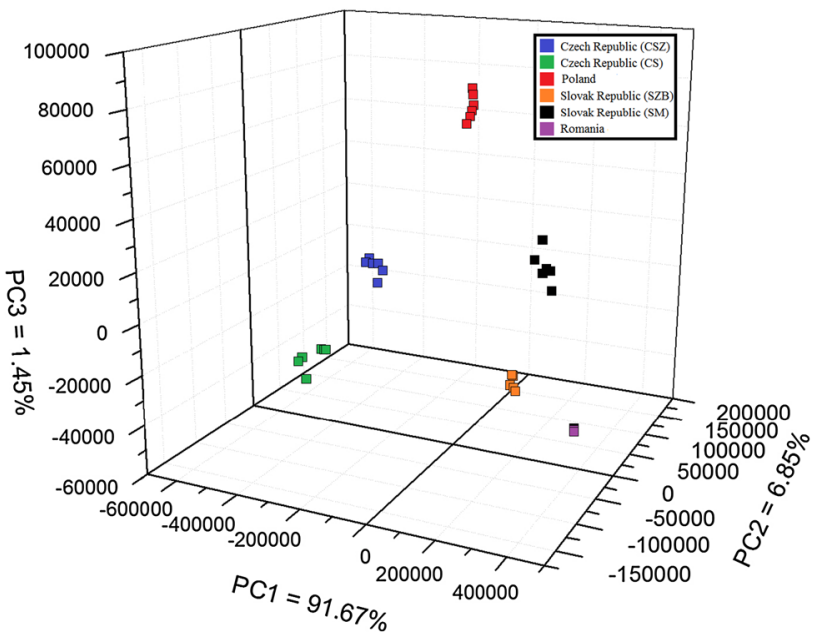

Fig. 3 The results of PCA 3D applied to plum spirits originating from different geographical regions; origin of samples was highlighted in: purple color Romania, red color Poland, green color Czech Republic (CS), blue color Czech Republic (CSZ), orange color Slovak Republic (SZB), black color Slovak Republic (SM), and six repetitions of all types of samples were done

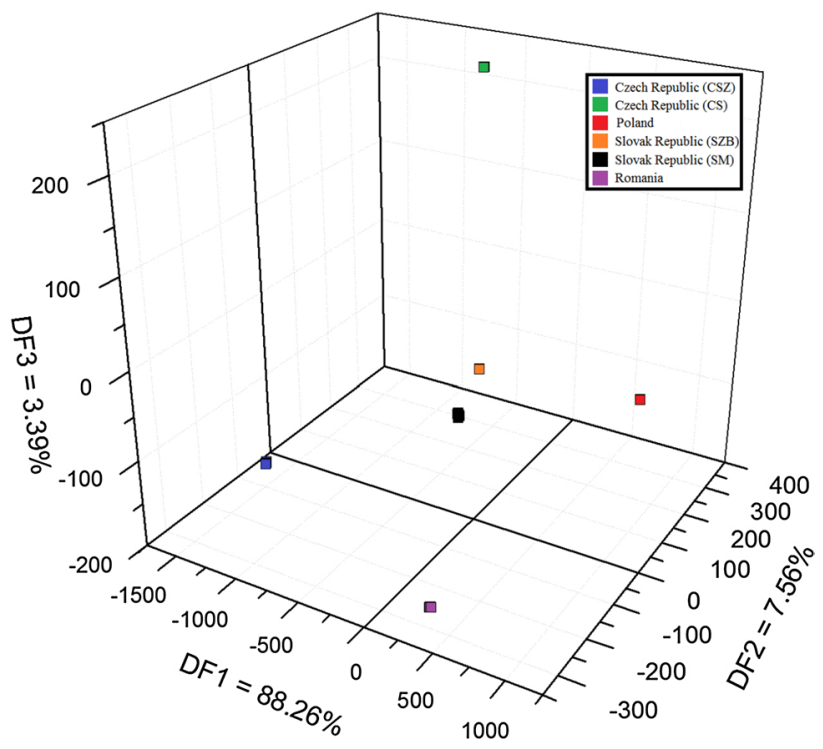

Fig. 4 The results of DFA 3D applied to plum spirits originating from different geographical regions; origin of samples was highlighted in: purple color Romania, red color Poland, green color Czech Republic (CS), blue color Czech Republic (CSZ), orange color Slovak Republic (SZB), black color Slovak Republic (SM), and six repetitions of all types of samples were done

groups is higher than the distance between two Slovakian groups. In comparison with the PCA 2D results, the points belonging to slivovitz are less dispersed. In the first quarter occur only points corresponding to a group of Polish plum spirit. However, the fourth quadrant includes only groups of Slovak beverages and plum spirit from Romania. For 
Fig. 5 The results of SIMCA applied to plum spirits originating from different geographical regions; origin of samples was highlighted in: purple color Romania, red color Poland, green color Czech Republic (CS), blue color Czech Republic (CSZ), orange color Slovak Republic (SZB), black color Slovak Republic (SM), and six repetitions of all types of samples were done. The plum spirit originating from Poland is a reference group

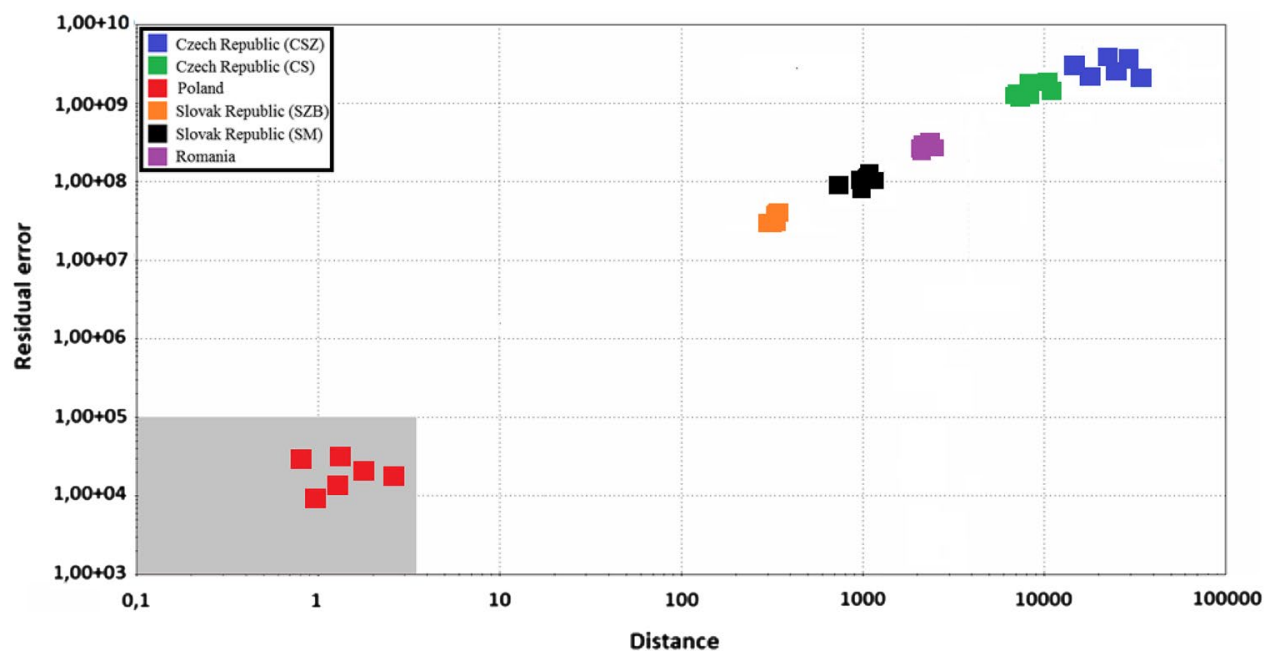

this reason, based on DFA 2D plot, it is apparent that the DF1 enables distinguishing between the plum spirits of different geographical origins.

In order to verify the results obtained using two-dimensional PCA and DFA, three-dimensional analysis was performed (Figs. 3, 4). Figure 3 shows PCA 3D results, where $\mathrm{PC} 1, \mathrm{PC} 2$ and $\mathrm{PC} 3$, respectively, contributed to $91.67 \%, 6.85 \%$ and $1.45 \%$ of the total variance. In Fig. 3, the Euclidean distance between two groups of plum spirits, Polish and Slovakian (SZB), is greater by about $50 \%$ than in PCA 2D. In case of DFA 3D, the distance between Slovakian (SM) and Romanian is much greater, about $158 \%$ of the distance in the DFA 2D plot. The distances between Slovak Republic (SZB) and Romanian was about $54 \%$ greater in DFA 3D. Also in obtained results, it can be observed slightly smaller distance differences (over $15 \%$ ) between groups of drinks from Slovakia and Romania. This is caused by the third value (z-coordinate). The reduction to only two dimensions resulted in a loss of information, so the use of statistical methods in three dimensions is always beneficial to final results. Both graphs show, despite variations in the distance between the groups, that it is possible to clearly distinguish groups from each other, which leads to the distinction of geographical origin. In every case of distinction between groups, determination of the $p$ value proved the null hypothesis to be true, which leads to the conclusion that the groups are uncorrelated.

In order to evaluate the suitability of an electronic nose for distinguishing of plum spirits of different geographical origins, the obtained data were analyzed by the SIMCA and SQC.

The SIMCA classification was used to compare all data to one group [31]. Analyses were performed using a classifier SIMCA in relation to the reference group:
Polish and Czech (CSZ). The area corresponding to the given class is shown on each plot as the gray rectangle in the left corner. In Fig. 5, validation score is 99, and thus, a significant distinction between Polish and other plum spirits groups was obtained. As in the case of plots in Figs. 1, 2, 3 and 4, the points corresponding to Polish plum spirit are in greater distance to other spirit groups. As in the case of other employed chemometric methods, the points corresponding to two plum spirits from Slovak Republic were closely located. In addition, it should be noted that the points corresponding to the Czech slivovitz are the most distant from the reference group. In Fig. 6, validation score is 97, and thus, a significant distinction between Czech (CSZ) and other plum spirits groups was obtained. Points corresponding to Czech (CS) were at the smallest distance from the gray area of confidence envelope. The distance between the reference group and the group corresponding to Czech (CS) was the smallest compared with the distances to other beverages.

In order to confirm the results obtained by SIMCA classifier, SQC was used. Figure 7 shows results of the SQC depending on Czech (CS) as reference group. The distance between Czech plum spirits is smaller than to other beverages. The largest distances are between Polish and Czech spirits and other spirits. Using the obtained results, it can be concluded that it is possible to distinguish Polish from Czech, Romanian and Slovakian plum spirits. In addition, it should be noted that the groups belonging to Slovakia are not far from each other. The Romanian group is also present in short distance away from them. For this reason, it can be concluded that the volatile profiles of Slovak and Romania are not significantly different, but they are still distinguishable. 
Fig. 6 The results of SIMCA applied to plum spirits originating from different geographical regions; origin of samples was highlighted in: purple color Romania, red color Poland, green color Czech Republic (CS), blue color Czech Republic (CSZ), orange color Slovak Republic (SZB), black color Slovak Republic (SM), and six repetitions of all types of samples were done. The plum spirit originating from $\mathrm{Czech}$ Republic (CSZ) is a reference group

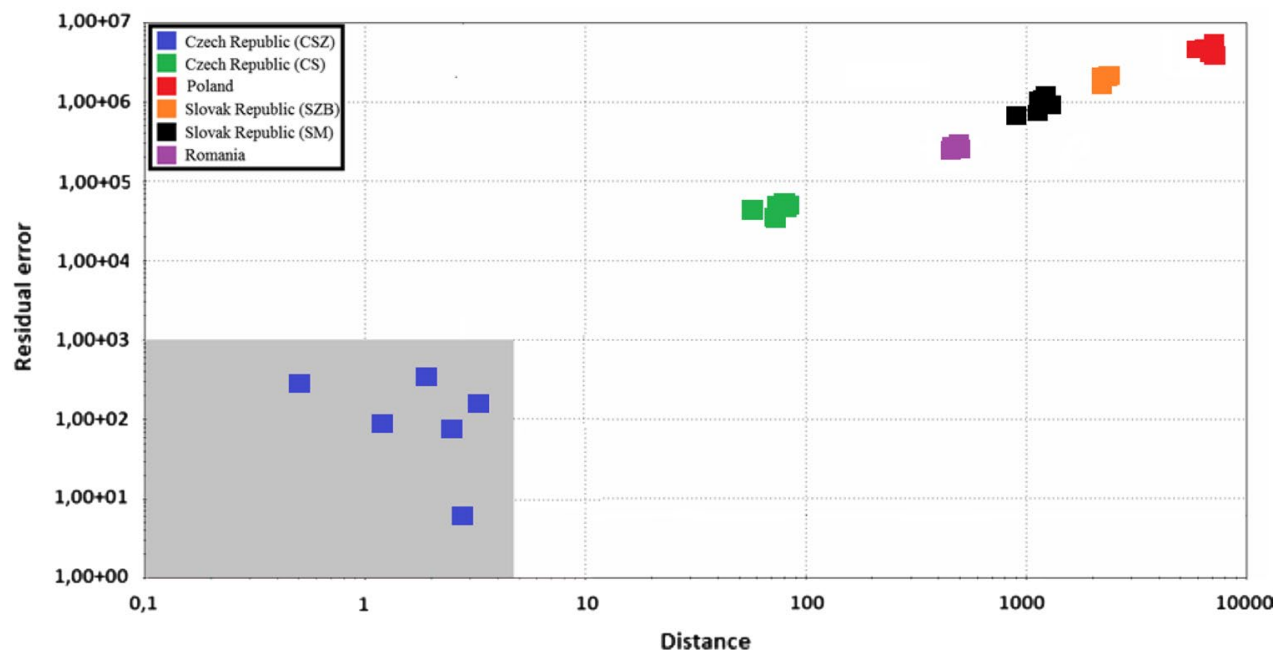

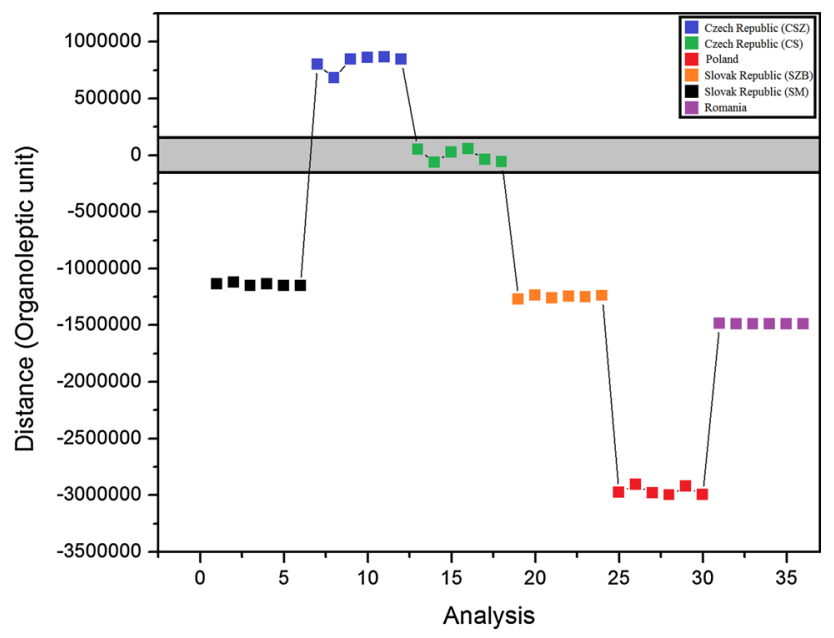

Fig. 7 The results of SIMCA applied to plum spirits originating from different geographical regions; origin of samples was highlighted in: purple color Romania, red color Poland, green color Czech Republic (CS), blue color Czech Republic (CSZ), orange color Slovak Republic (SZB), black color Slovak Republic (SM), and six repetitions of all types of samples were done. The plum spirit originating from Czech Republic (CS) is a reference group

\section{Conclusion}

This work reports, for the first time, the evaluation of an electronic nose based on fast GC for distinguishing between the volatile profiles of plum spirits of different geographical origins. It has been shown that it is possible to distinguish all analyzed groups of beverages. The electronic nose has shown that the highest distinction is between drinks from the Czech Republic and Poland. In addition, it has been shown that despite rather small differences between plum spirit from Slovak Republic and Romania it is still possible to distinguish them. All the applied chemometric methods turned out to be effective.
Analyses by PCA and DFA were done in two and three dimensions and demonstrated the ability to distinguish between all the groups of beverages. However, in the case of PCA and DFA, statistical methods in three dimensions should by used, because it has in all cases been beneficial to final results. Additionally, an analysis of the data using SIMCA and SQC was done in order to check the possibility of distinction of plum spirits according to their geographical origin. Moreover, despite the differences in the production of samples from Czech Republic, electronic nose has allowed for the distinction of samples from other beverages depending on the origin.

The positive results of the research have the potential to broaden the scope of scientific research in the use of electronic nose to investigate the geographical origin of plum spirits. These studies are the foundation to further work on discrimination of samples of plum spirits produced within a greater number of geographical regions. In the future, these tests may be used to study not only the geographical origin of fruit spirits, but also other spirit beverages.

Acknowledgments The authors acknowledge the financial support for this study by Grant No. 2012/05/B/ST4/01984 from the National Science Centre of Poland.

\section{Compliance with ethical standards}

Conflict of interest None.

Compliance with ethics requirements This article does not contain any studies with human or animal subjects.

Open Access This article is distributed under the terms of the Creative Commons Attribution 4.0 International License (http://creativecommons.org/licenses/by/4.0/), which permits unrestricted use, distribution, and reproduction in any medium, provided you give appropriate credit to the original author(s) and the source, provide a link to the Creative Commons license, and indicate if changes were made. 


\section{References}

1. spiritsEUROPE. http://www.spirits.eu/page.php?id=50\&parent $\mathrm{id}=10$. Accessed 28 Aug 2015

2. Regulation [EC] No. 110/2008 of the European Parliament and of the Council on the definition, description, presentation, labelling and the protection of geographical indications of spirit drinks and repealing Council Regulation (EEC) No. 1576/89

3. Śliwińska M, Wiśniewska P, Dymerski T, Wardencki W, Namieśnik J (2015) Flavour Fragr 30:197-207

4. Satora P, Tuszyński T (2008) J Sci Food Agric 88:167-174

5. Information from producer (Slivovitz Gold) http://en.rjelinek.cz/ products/detail 27-slivovitz-gold .html. Accessed 1 Sept 2015

6. Information from producer (Slivovitz) http://en.rjelinek.cz/products/detail 26-slivovitz .html. Accessed 1 Sept 2015

7. Tešević V, Nikićević N, Jovanović A, Djoković D, Vujisić L, Vučković I, Bonić M (2005) Food Technol Biotech 43:367-372

8. Pecić S, Veljović M, Despotović S, Leskošek-Čukalović I, Jadranin M, Tešević V, Nikšić M, Nikićević N (2012) Eur Food Res Technol 235:479-487

9. Bonić M, Tešević V, Nikićević N, Cvejić J, Milosavljević S, Vajs V, Mandić B (2013) J Serb Chem Soc 78:933-945

10. Balcerek M, Pielech-Przybylska K, Patelski P, Sapińska E, Księżopolska M (2013) J Food Sci 78:S770-S776

11. Satora P, Tuszyński T (2010) Food Microbiol 27:418-424

12. García-Llobodanin L, Achaerandio I, Ferrando M, Güell C, López F (2007) J Agric Food Chem 55:3462-3468

13. Di Natale C, Davide FAM, D'Amico A, Nelli P, Groppelli S, Sberveglieri G (1999) Sens Actuators B 33:83-88

14. Cynkar W, Dambergs R, Smith P, Cozzolino D (2010) Anal Chim Acta 660:227-231

15. Cozzolino D, Smyth HE, Cynkar W, Dambergs RG, Gishen M (2005) Talanta 68:382-387

16. Lozano J, Fernández MJ, Fontecha J, Aleixandre M, Santos JP, Sayago I, Arroyo T, Cabellos JM, Gutiérrez FJ, Horrillo MC (2006) Sens Actuators B 120:166-171
17. Aleixandre M, Lozano J, Gutiérrez J, Sayago I, Fernández MJ, Horrillo MC (2008) Sens Actuators B 131:71-76

18. Lozano J, Santos JP, Gutiérrez J, Horrillo MC (2007) Sens Actuators B 126:616-623

19. Rodriguez-Mendez ML (2016) Electronic noses and tongues in food science. Elsevier, Amsterdam

20. García M, Aleixandre M, Gutiérrez J, Horrillo M (2006) Sens Actuators B 113:911-916

21. Lozano J, Arroyo T, Santos JP, Cabellos JM, Horrillo MC (2008) Sens Actuators B 133:180-186

22. Spanier AM, Shahidi F, Parliment TH, Mussinan C, Ho CT, Tratras E (2001) Food flavours and chemistry: advances of the new millennium. RSC, Cambridge

23. Ragazzo-Sanchez JA, Chalier P, Chevalier D, Calderon-Santoyo M, Ghommidh C (2008) Sens Actuators B 134:43-48

24. Liu M, Han X, Tu K, Pan L, Tud J, Tang L, Liu P, Zhan G, Zhong Q, Xiong Z (2012) Food Control 26:564-570

25. Śliwińska M, Wiśniewska $P$, Dymerski T, Namieśnik J, Wardencki W (2014) J Agric Food Chem 19:1423-1448

26. Kundu K, Mitra S, Mazumdar D, Pal SK (2012) Perception and machine intelligence. Springer, New York

27. Marion B, Frances J (2012) Agro Food Ind Hi Tech 23:15-18

28. Yang Y, Zhao Y, Zhang S, Ni Y, Zhan J (2012) In: Daoliang L, Chen Y (ed) Computer and computing technologies in agriculture V. Springer, Heidelberg

29. Śliwińska M, Wiśniewska $P$, Dymerski $T$, Wardencki W, Namieśnik J (2016) Food Anal Method. doi:10.1007/ s12161-016-0448-z

30. Peng Q, Tian R, Chen F, Li B, Gao H (2015) Food Chem 178:301-305

31. Ghasemi-Varnamkhasti M, Saeid Mohtasebi S, Rodríguez-Méndez ML, Gomes AA, Ugulino Araújo MC, Galvăo RKH (2012) Talanta 89:286-291 